\title{
Trocas gasosas em folhas de sol e sombreadas de cajueiro anão em diferentes regimes hídricos ${ }^{1}$
}

\author{
Gas exchange in leaves of sun and shade of cashew in different water regimes
}

\author{
Michella de Albuquerque Lima ${ }^{2}$, Marlos Alves Bezerra ${ }^{3}$, Enéas Gomes Filho ${ }^{4}$, Ciro de Miranda Pinto ${ }^{2}$ e Joaquim \\ Enéas Filho ${ }^{4 *}$
}

\begin{abstract}
Resumo - Foram analisadas as variações sazonais nas taxas de trocas gasosas em lâminas foliares, sombreadas e a pleno sol, de cajueiro anão precoce (Anacardium occidentale L.), quando submetidas aos regimes de irrigação e de sequeiro. Os clones CCP 76 e BRS 189 foram mensalmente avaliados quanto ao seu desempenho fisiológico em relação à condutância estomática $(g)$, às taxas transpiratórias $(E)$ e fotossintéticas $(A)$, à temperatura foliar e à relação entre as concentrações interna e externa de $\mathrm{CO}_{2}\left(\mathrm{C}_{\mathrm{i}} / \mathrm{C}\right)$. O experimento foi conduzido entre setembro de 2006 e agosto de 2007, na estação experimental da Embrapa Agroindústria Tropical, localizada no município de Paraipaba, Ceará. As variáveis $A, g_{s}, E$ e $\mathrm{C}_{\mathrm{i}} / \mathrm{C}_{\mathrm{e}}$ foram afetadas apenas em função da época do ano e dos tipos de folhas. A maior influência nos fatores fisiológicos analisados ocorreu devido às condições em que as folhas estavam submetidas (sol ou sombra) e aos fatores meteorológicos e não à supressão da irrigação. Isto, possivelmente porque os resultados aqui obtidos estejam mais bem relacionados com as fases fenológicas da cultura do que com os tratamentos, demonstrando assim o conspícuo efeito físiológico da força dos drenos e da irradiância nessas plantas.
\end{abstract}

Palavras-chave - Anacardium occidentale. Estresse hídrico. Ecofisiologia vegetal.

\begin{abstract}
In this experiment we analyzed the seasonal variations in gas exchange rates of dwarf cashew (Anacardium occidentale L.) when exposed to irrigated and rainfed conditions. Full sun and shaded of clones CCP 76 and BRS 189 were monthly assessed for determination of stomatal conductance $\left(g_{s}\right)$, transpiration rate $(E)$ and photosynthesis $(A)$, internal and external $\mathrm{CO}_{2}\left(\mathrm{C}_{\mathrm{i}} / \mathrm{C}_{\mathrm{e}}\right)$ and leaf temperature. The experiment was carried out between September 2006 and August 2007, at the experimental station of Embrapa Agroindústria Tropical, located at Paraipaba County, state of Ceará, Brazil. In general, the variables $A, g_{s}, E$ and $\mathrm{C}_{\mathrm{i}} / \mathrm{C}_{\mathrm{e}}$ were affected only in terms of time of year and types of leaves. Light influenced the physiological factors rather than suppression of water. Possibly because the results obtained here are better related to the phenological stages than with the treatments, demonstrating a conspicuous physiological effect of the strength of the drains and the irradiance in these plants.
\end{abstract}

Key words - Anacardium occidentale. Water stress. Ecophysiology.

\footnotetext{
* Autor para correspondência

${ }^{1}$ Recebido para publicação em 13/04/2010; aprovado para 13/11/2010

Pesquisa financiada pelo CNPq, texto extraído da dissertação do primeiro autor

${ }^{2}$ Programa de Pós-Graduação em Agronomia/Fitotecnia, Universidade Federal do Ceará, Av. Humberto Monte, S/N, Campus do Pici, Fortaleza-CE, Brasil,60.455-970,michella_bio@yahoo.com.br, ciro.pinto@gmail.com

${ }_{3}^{3}$ Pesquisador da Embrapa Agroindústria Tropical, CNPAT/EMBRAPA, Fortaleza-CE, Brasil, 60.511-110, marlos@cnpat.embrapa.br

${ }^{4}$ Departamento de Bioquímica de Biologia Molecular, Universidade Federal do Ceará, Bolsista do CNPq, Fortaleza-CE, Brasil, 60.455-970, egomesf@ufc.br,joaquime@ufc.br
} 


\section{Introdução}

A cultura do cajueiro (Anacardium occidentale L.) é de grande importância para a agricultura de regiões semiáridas, contribuindo para o desenvolvimento sócioeconômico de diversas regiões do mundo, incluindo a região Nordeste do Brasil (BEZERRA et al., 2007). Nessa região, encontra-se sob regime irrigado e não irrigado, sendo esse último também denominado regime de sequeiro.

Apesar de a irrigação ser comprovadamente benéfica para a cultura, torna-se imperiosa a racionalização do uso da água, seja em virtude da necessidade de preservação dos recursos hídricos, seja pelo alto custo energético necessário para o funcionamento do sistema de irrigação. Nas regiões semiáridas, como é o caso da região supracitada, cuja drenagem é deficiente e as águas subsuperficiais costumam ser ricas em sais solúveis, o regime de seca e o manejo inadequado da irrigação elevam enormemente o risco de salinização do solo, podendo promover os estresses salino e hídrico. Quaisquer desses estresses resultam na redução da produtividade.

Por outro lado, trabalhos referentes às respostas fisiológicas da cultura do cajueiro à irrigação ou às condições de sequeiro são insipientes ou pouco conclusivos. Alguns autores mostram que a capacidade fotossintética das plantas pode ser afetada negativamente pela supressão da irrigação, podendo essa redução influenciá-la de forma direta, através da desidratação do aparato fotossintético, ou pelo efeito indireto associado ao fechamento estomático (LAWLOR; CORNIC, 2002). Com a severidade do estresse hídrico, podem ocorrer algumas outras mudanças tais como o aumento na resistência mesofílica à difusão de $\mathrm{CO}_{2}$, alterações nas atividades das enzimas das fases bioquímicas da fotossíntese, do metabolismo dos carboidratos e do nitrogênio (PALLESCHI et al., 1997) e o estoque de fósforo inorgânico na planta pode ser alterado (KUWAHARA; SOUZA, 2009). Contudo, são poucos os estudos sobre os efeitos do déficit hídrico em plantas adultas de cajueiro anão precoce.

Outro fator ainda não estudado em plantas de cajueiro anão precoce é o sombreamento que as folhas da parte superior exercem nas localizadas internamente na copa dessas árvores. O sombreamento promove níveis diferenciados de radiação e temperatura que podem reduzir a atividade fotossintética, a biomassa e a produção, podendo ainda afetar o transporte de fotoassimilados e a relação fonte-dreno (SOUZA et al., 2001). Segundo Oliveira e Lima (2000) a observação casual sugere que fatores climáticos como temperatura e radiação solar exercem influência sobre a produção e que um lado da planta pode apresentar maior produção do que o outro.
Assim, a irrigação no período adequado do ciclo da cultura possibilita a economia dos recursos hídricos e um melhor desempenho da cultura, possibilitando ainda uma expansão da área de cultivo. Estudos que demonstrem a relação existente entre os tipos de folha dentro da copa, bem como sua dependência da água permite podas mais direcionadas em períodos apropriados. Para tanto, é fundamental o conhecimento dos processos fisiológicos fundamentais dessa cultura, tais como as relações hídricas e as trocas gasosas. Nesse contexto, objetivou-se determinar os parâmetros ecofisiológicos em lâminas foliares submetidas a pleno sol e sombreamento em dois clones de cajueiro anão precoce em cultivos irrigado e não irrigado.

\section{Material e métodos}

O experimento foi conduzido na estação experimental da Embrapa Agroindústria Tropical, localizada no município de Paraipaba, Ceará $\left(3^{\circ} 26^{\prime} \mathrm{S}\right.$ e $39^{\circ} 08^{\prime} \mathrm{O}$ ), com altitude de $31 \mathrm{~m}$ e distância de $100 \mathrm{~km}$ da capital, Fortaleza. Avaliaram-se as trocas gasosas em lâminas foliares a pleno sol e sombreadas, em plantas adultas de clones de cajueiro (A. occidentale L.) anão precoce, CCP 76 e BRS 189, cultivados sob regime irrigado e não irrigado no período de setembro de 2006 a agosto de 2007. Foram consideradas folhas sombreadas aquelas que estavam na parte interna mediana da copa das plantas. Durante o período avaliado, foram mensurados os dados climáticos como temperatura máxima e mínima, umidade relativa do ar e pluviometria, os quais foram obtidos de uma estação meteorológica instalada próxima à área do experimento.

O delineamento experimental estabelecido foi em blocos ao acaso, num fatorial $2 \times 2 \times 12$. O primeiro fator foi representado pelos regimes hídricos: irrigado e não irrigado, o segundo, pelas condições em que estavam submetidas as folhas: pleno sol e sombreamento e o terceiro pelos meses do ano. Cada tratamento constou de quatro repetições, com quatro plantas por parcela.

O espaçamento utilizado foi de $8 \mathrm{~m} \mathrm{x} 6 \mathrm{~m} \mathrm{em}$ uma área de 0,15 ha. Visando evitar a influência dos experimentos vizinhos na mesma área da estação experimental sobre as parcelas, bem como protegê-las de fatores que viessem a provocar um aumento no erro experimental, foram plantados clones de cajueiro anão precoce CCP 09 na bordadura de ambos os clones.

A irrigação teve início em maio de 2006, utilizandose microaspersores com vazão de $50 \mathrm{~L} \mathrm{~h}^{-1}$, cujo turno de rega ocorria três vezes por semana, durante $2 \mathrm{~h}$. Quando necessário, procedeu-se ao tratamento fitossanitário com 
herbicidas de acordo com as recomendações do fabricante. As plantas receberam adubação via fertirrigação, a cada dois meses, inclusive no tratamento não irrigado. Entre os meses de janeiro e maio de 2007, as plantas do tratamento irrigado não receberam água de irrigação, devido ao regime de chuvas típico do período que fez igualar a umidade do solo para ambos os tratamentos.

Foram mensuradas as taxas de fotossíntese $(A) \mathrm{e}$ de transpiração $(E)$, a condutância estomática ao vapor de água $\left(g_{s}\right)$ e a relação entre as concentrações interna e externa de $\mathrm{CO}_{2}\left(\mathrm{C}_{\mathrm{i}} / \mathrm{C}_{\mathrm{e}}\right)$, sendo, para isso, utilizado um analisador portátil de gás no infravermelho - IRGA (modelo LCi, ADC BioScientific, Inglaterra), em sistema aberto sob luz saturante e condições ambientes de temperatura e concentração de $\mathrm{CO}_{2}$. As medições foram realizadas mensalmente de setembro de 2006 a agosto de 2007, no horário compreendido entre 9 e $12 \mathrm{~h}$. Durante as análises, as folhas no estádio adulto e totalmente expandidas, foram mantidas em suas posições originais conforme descrito por DaMatta et al. (2007) e Silva et al. (2004). Com os dados de trocas gasosas foi determinada a eficiência no uso de água através da relação $A / E$ e a eficiência intrínseca do uso da água $\left(A / g_{s}\right)$.

\section{Resultados e discussão}

A condutância estomática $\left(g_{s}\right)$ foi praticamente constante durante o período seco (setembro/2006 a janeiro/2007) para ambos os clones e condições de luminosidade das folhas. Porém, em média, foi ligeiramente inferior àquela do período chuvoso (fevereiro a julho/2007) (FIG. 1).

Entre os tipos de folha, $\mathrm{a}_{\mathrm{s}}$ se mostrou diferente. Nas folhas de sol variou de 0,23 a 0,50 , com valores médios de $0,33 \mathrm{~mol} \mathrm{~m}^{-2} \mathrm{~s}^{-1}$, enquanto que nas folhas de sombra ficou entre 0,12 e 0,33 , com valores médios de $0,20 \mathrm{~mol}^{-2} \mathrm{~s}^{-1}$. Segundo Larcher (2000) a resistência estomática é baixa em plantas de sol e relativamente alta em plantas de sombra.

Quando comparados os dois regimes de irrigação, a condutância estomática foi pouco variável ao longo dos meses. Dessa forma, as plantas de cajueiro anão precoce não irrigadas podiam não estar submetidas a uma condição de estresse hídrico. Em estresses moderados e de curta duração, são poucas as alterações observadas no aparelho fotossintético (SOUZA; CARDOSO, 2003). Mesmo sendo o cajueiro anão precoce uma planta de porte baixo, é necessário considerar o que ocorre na parte externa e interna da copa, pois esse fato demonstra que o efeito da luminosidade na fisiologia dos estômatos foi, provavelmente, maior que o efeito da irrigação.
Em geral, as taxas fotossintéticas dos clones CCP 76 e BRS 189 foram, em média, duas vezes maiores em folhas a pleno sol quando comparadas às folhas sombreadas. Por outro lado, não houve diferenças significativas entre os regimes de irrigação independente do clone ou tipo de folha (FIG. 2).

Corroboram esses dados os resultados encontrados por Amorim et al. (2010), estudando plantas adultas de cajueiro anão precoce no município de Pacajus, Ceará, sob condições de sequeiro e irrigadas com água salina. Segundo Habermann et al. (2003), a arquitetura da planta determina a quantidade de luz interceptada por unidade de área foliar, o que resulta em baixos índices fotossintéticos em condições de sombreamento. Provavelmente, a arquitetura da planta e a menor irradiância recebida pelas folhas internas da copa promoveram as reduções nas taxas fotossintéticas em folhas de sombra.

Nas folhas a pleno sol, houve diferença significativa entre os clones para os diferentes regimes hídricos. Em geral, o clone CCP 76, quando irrigado, apresentou as maiores taxas de assimilação de $\mathrm{CO}_{2}$, respondendo melhor ao suprimento de água do que o clone BRS 189 , cujas taxas de $A$ praticamente não variaram entre os tratamentos. Segundo Paiva e Barros (2004), o clone CCP 76 é recomendado tanto para o cultivo de sequeiro quanto irrigado, enquanto o clone BRS 189 é mais adaptado ao sistema irrigado. Entretanto, apesar de sua proximidade genética com o clone CCP 76, por ser proveniente do cruzamento entre os clones de cajueiro anão precoce CCP 1001 e CCP 76, este apresentou taxas fotossintéticas menos satisfatórias nesse experimento. Mesmo sendo a assimilação de $\mathrm{CO}_{2}$ um bom parâmetro para estudos de tolerância ao estresse hídrico, conforme preconizam Santos e Carlesso (1998), este não é o único fator a ser considerado e com os dados deste estudo não foi possível concluir tal característica para os clones estudados.

Por outro lado, pode ter ocorrido efeito da fase de crescimento da planta sobre a fotossíntese, com uma mudança na demanda por fotoassimilados nos drenos. O crescimento e brotação de novos ramos, bem como a floração, foram mais vigorosos (maior demanda dos drenos) a partir de maio. Como as medidas de trocas gasosas foram realizadas em folhas com aproximadamente as mesmas idades e a umidade do solo foi mantida em condições ideais, as variações observadas devem estar relacionadas com as mudanças climáticas e/ou com o estádio fisiológico das plantas. Machado et al. (2002), estudando a variação sazonal das trocas gasosas em folhas de laranjeira "Valência", sugerem que a queda em $A$ e na $g_{s}$ ocorridas nessas plantas nos meses mais quentes está relacionada à diminuição do crescimento da planta, 


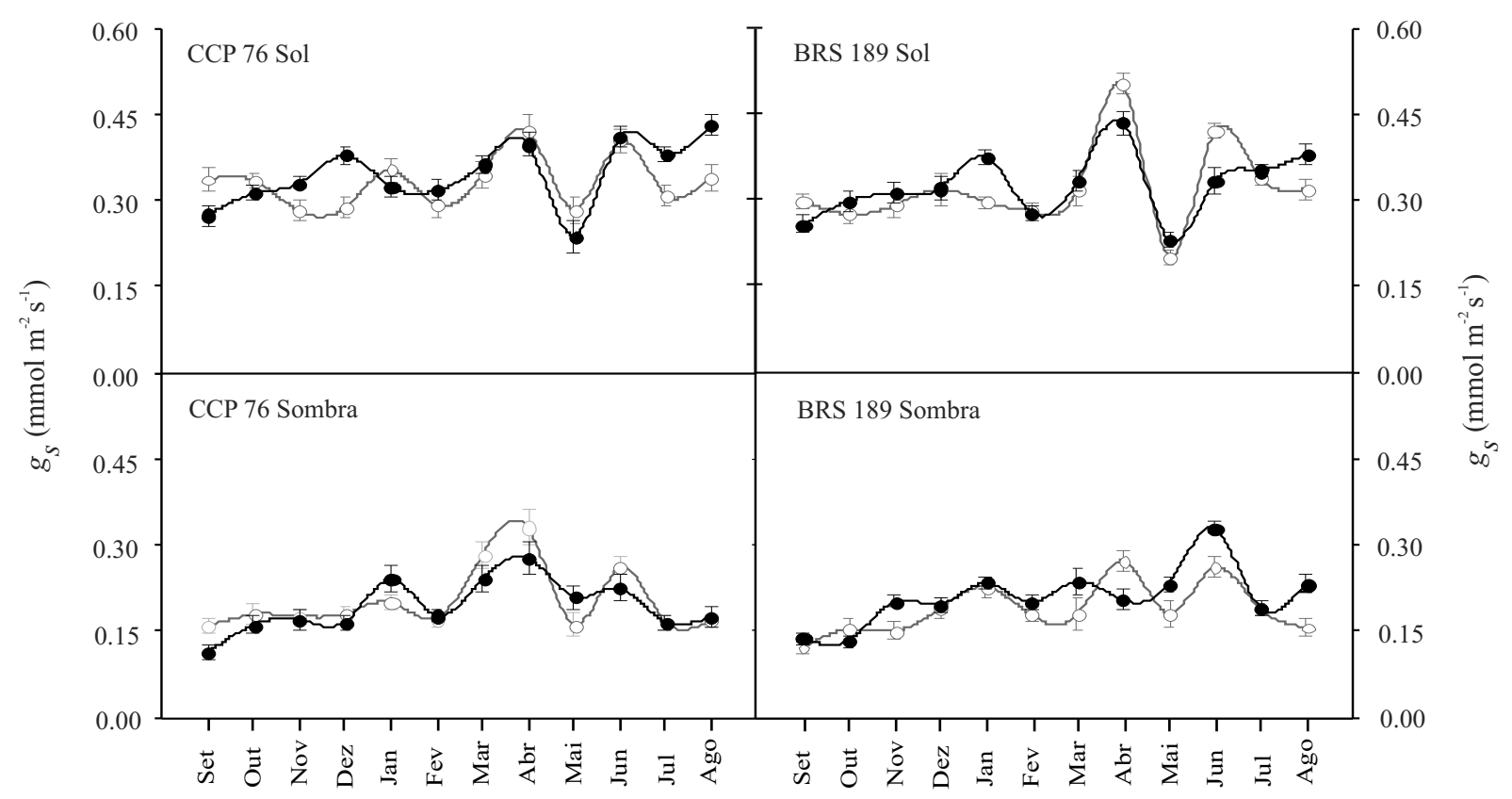

Figura 1 - Condutância estomática $\left(g_{s}\right)$ de folhas a pleno sol e sombreadas de plantas não irrigadas $(-\circ)$ e irrigadas $(\bullet-)$ dos clones de cajueiro anão precoce CCP 76 e BRS 189

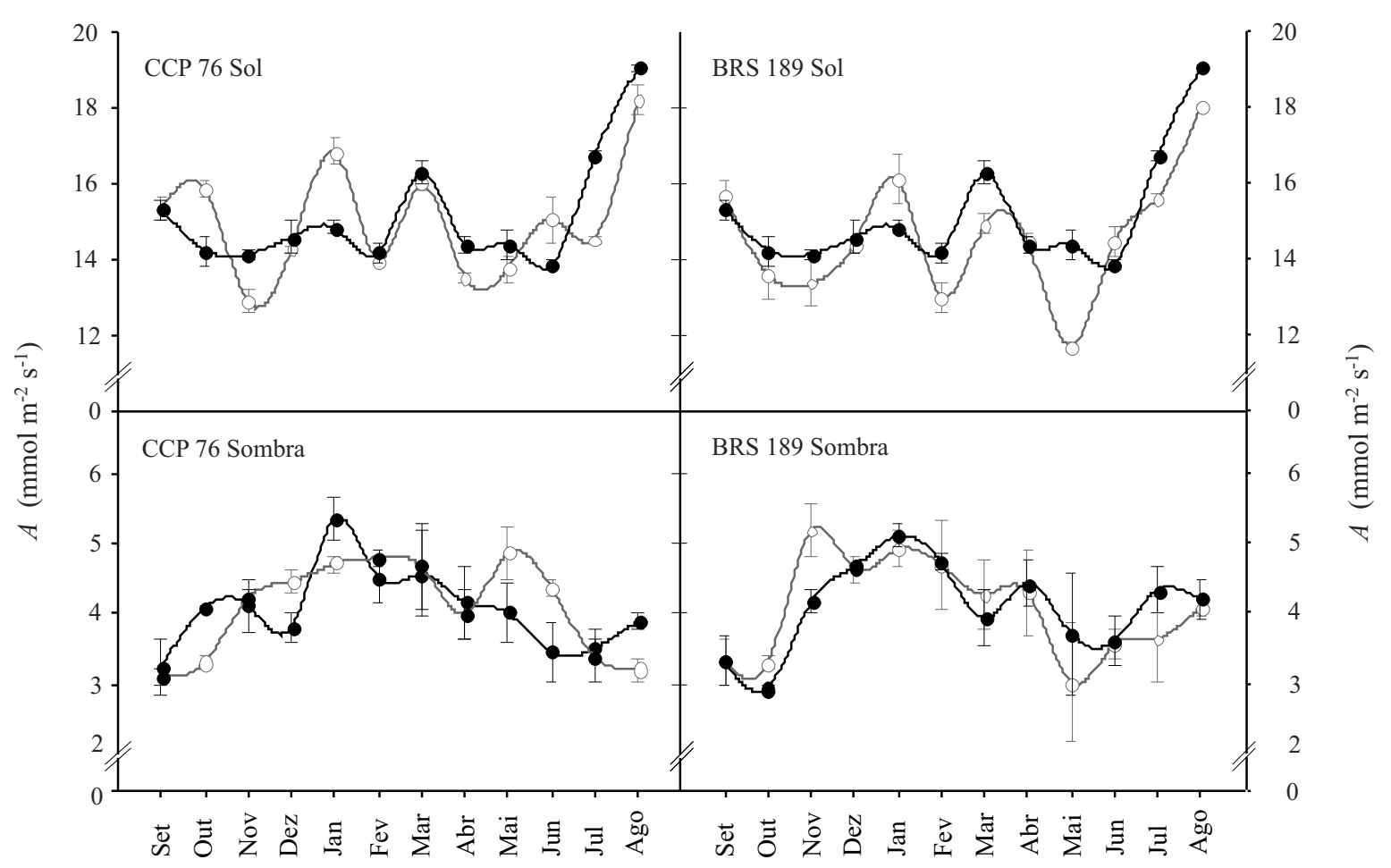

Figura 2 - Fotossíntese líquida $(A)$ de folhas a pleno sol e sombreadas, de plantas não irrigadas $(-\circ)$ e irrigadas $(\bullet \bullet)$, dos clones de cajueiro anão precoce CCP 76 e BRS 189

afetando as relações fonte-dreno. Concordam com esses dados o trabalho realizado por Cavalcanti et al. (2008), com o clone CCP 76 submetido ao estresse hídrico em diferentes fases fenológicas, onde foi observado que a resistência estomática foi extremamente afetada nas fases de crescimento e reprodução dessas plantas. 
O fechamento dos estômatos causou alterações na eficiência intrínseca do uso de água $\left(A / g_{s}\right)$ (FIG. 3). Ao longo do período experimental as folhas de sol de ambos os clones tiveram sua eficiência reduzida no período chuvoso (março a julho/2007), principalmente nos tratamentos irrigados.

Nos tratamentos não irrigados, apesar de também sofrerem queda na relação $A / g_{s}$ esta foi bem menos pronunciada, demonstrando uma maior eficiência das plantas de sequeiro quanto às taxas fotossintéticas. Por outro lado, as folhas de sombra comportaramse de forma contrária, sendo observada uma menor relação $A / g$ durante o período seco (setembro/2006 a janeiro/2007) do que no período chuvoso. MachadoFilho et al. (2006), estudando a variação sazonal das trocas gasosas em folhas de mamoeiro durante a época seca e chuvosa, observaram que os valores da relação $\mathrm{A} / \mathrm{g}_{s}$ foram cerca de $50 \%$ superiores na época seca em decorrência do fechamento estomático. Essas observações são confirmadas pelos autores MachadoFilho (2002) e Ghannoum et al. (2003) os quais estabeleceram relações entre o mecanismo de abertura e fechamento dos estômatos e diversos fatores do meio e da própria planta que atuam sobre os mesmos.

As taxas transpiratórias (E) não apresentaram diferenças significativas quanto aos clones (FIG. 4). Contudo, entre os tipos de folhas foram observadas menores $E$ para as folhas de sombra que variaram de 1,31 a 3,94, com valores médios de $3,14 \mathrm{mmol} \mathrm{m}^{-2} \mathrm{~s}^{-1}$, no regime não irrigado e 1,55 a 4,78, com valores médios de $3,28 \mathrm{mmol} \mathrm{m}^{-2} \mathrm{~s}^{-1}$, no regime irrigado. Para as folhas de sol, a variação foi de 2,30 a 6,49 , com valores médios de 4,91 mmol m $\mathrm{m}^{-1}$ e 2,45 a 7,49, com valores médios de $5,10 \mathrm{mmol} \mathrm{m}^{-2} \mathrm{~s}^{-1}$ nos regimes não irrigado e irrigado, respectivamente. Os valores de $E$ nas folhas de sombra e a pleno sol confirmam aqueles observados para a $g_{s}$, que apresentaram a mesma tendência.

De setembro/2006 a janeiro/2007, período em que foram observados os maiores valores de temperatura do ar, as mais baixas taxas de umidade relativa e não houve ocorrência de precipitação (FIG. 5), a E (FIG. 4), manteve-se praticamente constante e a $g_{s}$ (FIG. 1) seguiu o mesmo comportamento.

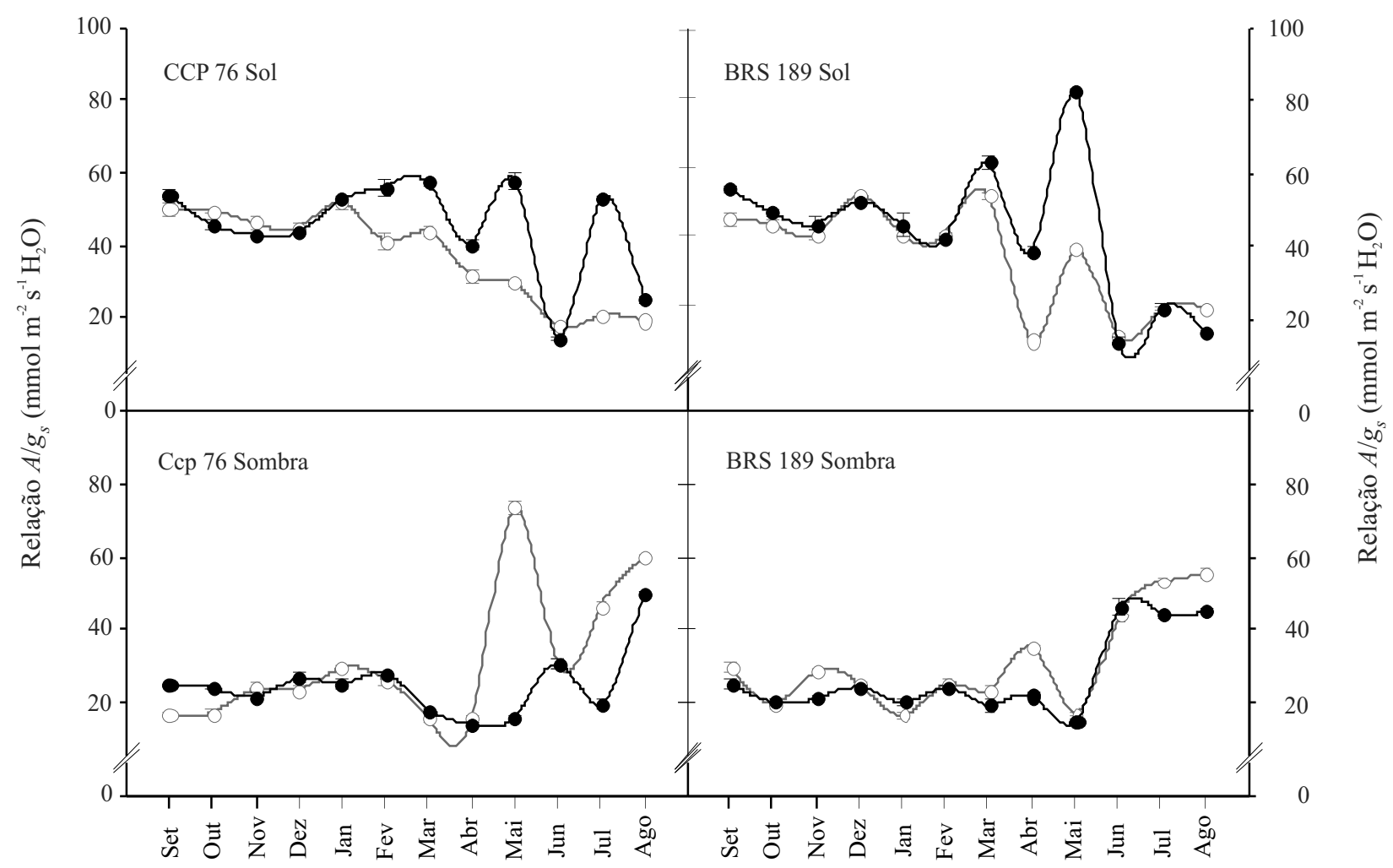

Figura 3 - Eficiência intrínseca do uso da água $\left(A / g_{s}\right)$ de folhas a pleno sol e sombreadas de plantas não irrigadas ( --$)$ e irrigadas ( - -) dos clones de cajueiro anão precoce CCP 76 e BRS 189 


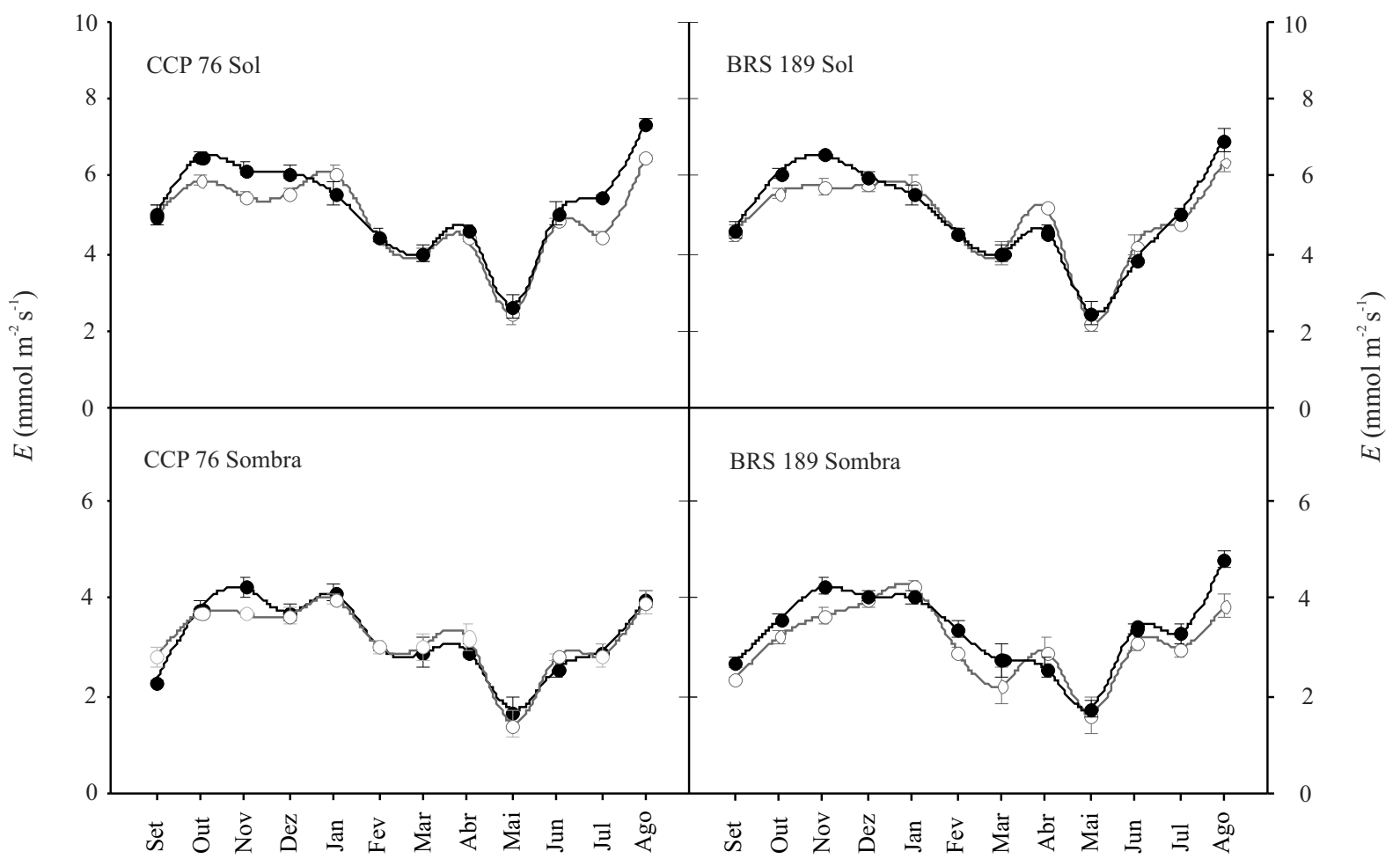

Figura 4 - Taxa transpiratória $(E)$ de folhas a pleno sol e sombreadas de plantas não irrigadas $(-\circ)$ e irrigadas $(-\bullet)$ dos clones de cajueiro anão precoce CCP 76 e BRS 189

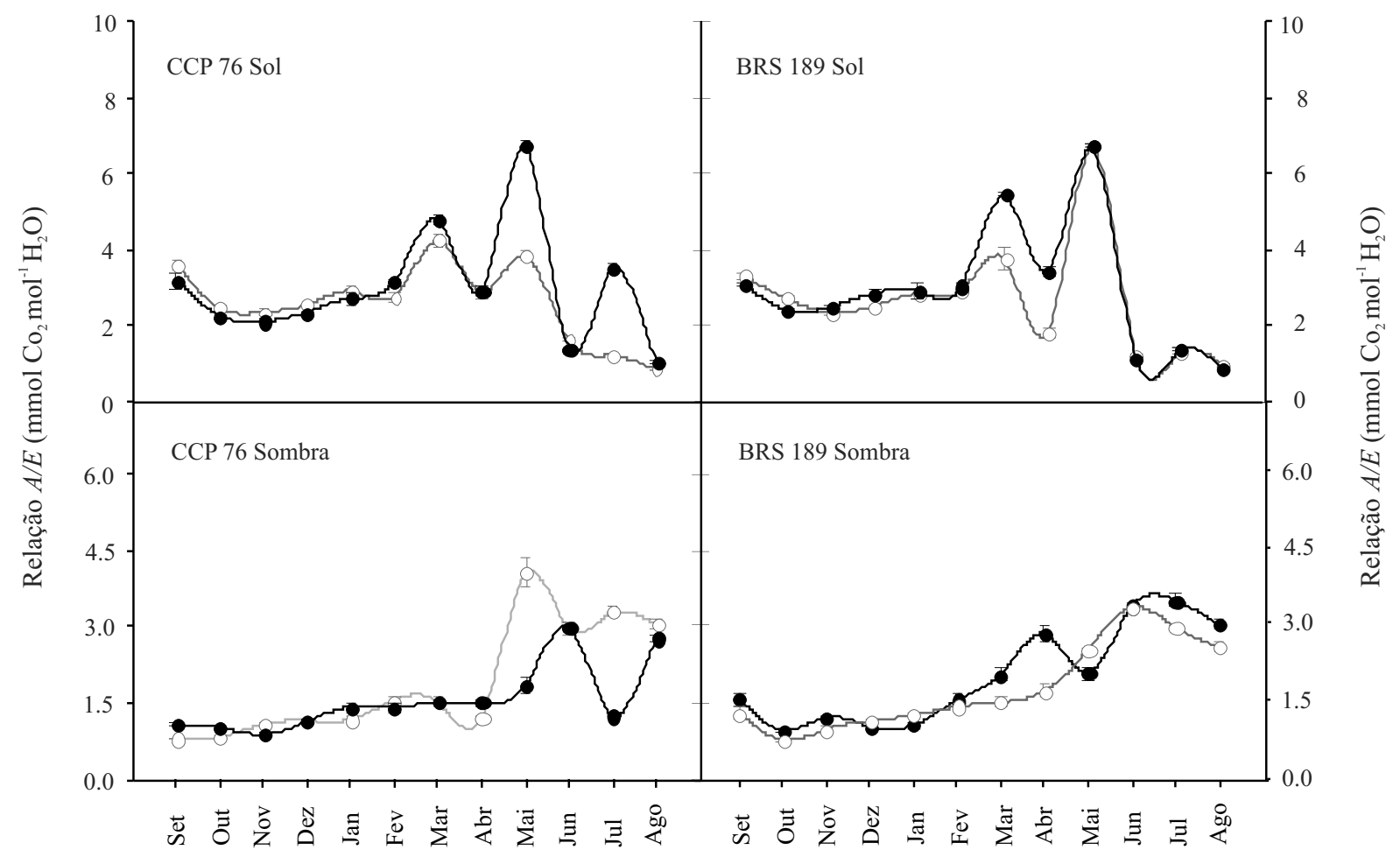

Figura 5 - Relação entre a taxa fotossintética e a taxa transpiratória $(A / E)$ de folhas a pleno sol e sombreadas de plantas não irrigadas $(-\circ)$ e irrigadas $(\bullet-)$ dos clones de cajueiro anão precoce CCP 76 e BRS 189 
De acordo com Santos e Carlesso (1998), o suprimento de água às plantas é determinado pela habilidade da cultura em utilizar a água armazenada no solo, enquanto a demanda da atmosfera, por outro lado, está relacionada à combinação dos fatores meteorológicos interagindo com o dossel vegetativo da cultura.

Esse fato também foi confirmado pela correlação positiva existente entre as taxas transpiratórias $(E)$ das folhas de sol de ambos os clones e a temperatura do ar $\left(\mathrm{T}_{\mathrm{ar}}\right)\left(E \times \mathrm{T}_{\mathrm{ar}}\right)$ e a correlação negativa entre $E$ e a umidade relativa (UR) $(E \times \mathrm{UR})(\mathrm{TAB} .1)$.

Segundo Castro Neto (2003), em uma situação de boa disponibilidade de água, as plantas cultivadas geralmente apresentam altas taxas de transpiração. À medida que a água do solo se torna escassa, a planta começa a reduzir sua taxa transpiratória para diminuir a perda de água e economizar a água disponível no solo (KANG et al., 2003; MACHADO-FILHO, 2002).

Cavalcanti Júnior et al. (2003), trabalhando com mudas enxertadas do clone CCP76 sob estresse hídrico, durante seis dias, observaram que houve recuperação da condutância estomática e aumento nas taxas transpiratórias após a reidratação.

Os resultados aqui obtidos mostram que, com a chegada das chuvas, a condutância estomática aumentou, entretanto isso não foi totalmente revertido com relação às taxas transpiratórias e sim com as taxas fotossintéticas. Isso pode ser visto na Figura 6, quando se observa alta relação entre $A / E$, indicando uma eficiência do uso de água por essas plantas.

Entretanto, a partir do mês de janeiro, quando tem início o período das chuvas, verificou-se a ocorrência de uma menor resistência estomática com oscilações nas taxas transpiratórias. Apesar disso, as plantas transpiraram menos do que no período seco. $\mathrm{O}$ efeito causado na redução da transpiração pode ter sido devido a uma maior eficiência das folhas em assimilar o $\mathrm{CO}_{2}$ A competição entre a molécula de $\mathrm{CO}_{2}$ e a da $\mathrm{H}_{2} \mathrm{O}$ pode ter reduzido a perda de água pelos estômatos. Deste modo, a luminosidade pode ter influenciado nas taxas transpiratórias dessas plantas, fato que se observa pela diminuição das temperaturas foliares dessas plantas durante a ocasião citada (FIG. 7).

A temperatura das folhas $\left(\mathrm{T}_{\mathrm{f}}\right)$ de sol variou de 34,6 a 39,4 no regime irrigado e 34,0 a 39,4 no não irrigado e nas folhas de sombra de 33,0 a $38,4{ }^{\circ} \mathrm{C}$ (irrigado) e 33,4 a $37,4{ }^{\circ} \mathrm{C}$ (não irrigado). Contudo, $\left(\mathrm{T}_{\mathrm{ar}}\right)$ (FIG.5), durante o período experimental, foi inferior à das folhas. Essa variou de 31,4 a $33,6{ }^{\circ} \mathrm{C}$, não sendo, portanto, a $\mathrm{T}_{\mathrm{f}}$ afetada pela temperatura do ar (TAB. 1).

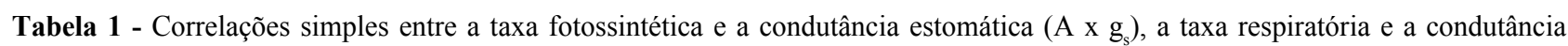
estomática $\left(\mathrm{E} \mathrm{x} \mathrm{g} \mathrm{g}_{\mathrm{s}}\right)$, as temperaturas da folha e do $\operatorname{ar}\left(\mathrm{T}_{\mathrm{f}} \mathrm{x} \mathrm{T}_{\mathrm{ar}}\right)$, a temperatura da folha e a umidade relativa do ar $\left(\mathrm{T}_{\mathrm{f}} \mathrm{x} U R\right)$, a temperatura da folha e a condutância estomática $\left(\mathrm{T}_{\mathrm{f}} \times \mathrm{g}_{\mathrm{s}}\right)$, a temperatura da folha e taxa transpiratória $\left(\mathrm{T}_{\mathrm{f}} \mathrm{x}\right)$, a taxa transpiratória e temperatura do $\operatorname{ar}\left(\mathrm{E} \mathrm{x} \mathrm{T}_{\mathrm{ar}}\right)$ e a taxa transpiratória e a umidade Relativa (E x UR) em folhas de sol (Sol) e de sombra (Sb) de dois clones de cajueiro anão precoce (CCP76 e BRS 189), sob condições irrigadas e não irrigadas, entre setembro de 2006 e agosto de 2007

\begin{tabular}{|c|c|c|c|c|c|c|c|c|c|c|}
\hline & & & $A \times g_{s}$ & $E \times g_{s}$ & $\mathrm{~T}_{\mathrm{f}} \mathrm{x}_{\mathrm{ar}}$ & $\mathrm{T}_{\mathrm{f}} \mathrm{x} \mathrm{UR}$ & $\mathrm{T}_{\mathrm{f}} \mathrm{xg}_{\mathrm{s}}$ & $\mathrm{T}_{\mathrm{f}} \mathrm{x} E$ & $E \mathrm{x} \mathrm{T}_{\mathrm{ar}}$ & $E \mathrm{x}$ UR \\
\hline \multirow{4}{*}{$\begin{array}{c}\text { CCP } \\
76\end{array}$} & \multirow{2}{*}{$\begin{array}{l}\text { Não } \\
\text { Irrigado }\end{array}$} & $\mathrm{Sb}$ & $0,249^{\text {ns }}$ & $0,033^{\text {ns }}$ & $0,109^{\text {ns }}$ & $-0,004^{\text {ns }}$ & $-0,193^{\text {ns }}$ & $0,099^{\text {ns }}$ & $0,496^{\text {ns }}$ & $-0,567^{\mathrm{ns}}$ \\
\hline & & Sol & $0,269^{\mathrm{ns}}$ & $0,136^{\mathrm{ns}}$ & $0,386^{\mathrm{ns}}$ & $-0,146^{\mathrm{ns}}$ & $-0,473^{\mathrm{ns}}$ & $0,235^{\mathrm{ns}}$ & $0,743^{*}$ & $-0,717^{*}$ \\
\hline & \multirow{2}{*}{ Irrigado } & $\mathrm{Sb}$ & $0,544^{\mathrm{ns}}$ & $-0,07^{\mathrm{ns}}$ & $0,470^{\mathrm{ns}}$ & $-0,325^{\text {ns }}$ & $-0,155^{\mathrm{ns}}$ & $0,313^{\text {ns }}$ & $0,549^{\text {ns }}$ & $-0,628^{*}$ \\
\hline & & Sol & $0,657^{*}$ & $0,519^{\text {ns }}$ & $0,668^{*}$ & $-0,384^{\text {ns }}$ & $-0,316^{\mathrm{ns}}$ & $0,231^{\mathrm{ns}}$ & $0,722 *$ & $-0,745^{*}$ \\
\hline \multirow{4}{*}{$\begin{array}{c}\text { BRS } \\
189\end{array}$} & \multirow{2}{*}{$\begin{array}{l}\text { Não } \\
\text { Irrigado }\end{array}$} & $\mathrm{Sb}$ & $0,146^{\mathrm{ns}}$ & $0,145^{\mathrm{ns}}$ & $0,254^{\mathrm{ns}}$ & $-0,108^{\mathrm{ns}}$ & $-0,029^{\mathrm{ns}}$ & $0,300^{\text {ns }}$ & $0,642^{\text {ns }}$ & $-0,620^{*}$ \\
\hline & & Sol & $0,321^{\mathrm{ns}}$ & $0,37^{\mathrm{ns}}$ & $0,670^{*}$ & $-0,384^{\mathrm{ns}}$ & $-0,328^{\mathrm{ns}}$ & $0,353^{\mathrm{ns}}$ & $0,614^{*}$ & $-0,748^{*}$ \\
\hline & \multirow{2}{*}{ Irrigado } & $\mathrm{Sb}$ & $0,227^{\mathrm{ns}}$ & $0,049^{\text {ns }}$ & $0,314^{\mathrm{ns}}$ & $0,209^{\text {ns }}$ & $0,265^{\mathrm{ns}}$ & $0,427^{\mathrm{ns}}$ & $0,426^{\mathrm{ns}}$ & $-0,661^{*}$ \\
\hline & & Sol & $0,291^{\mathrm{ns}}$ & $0,276^{\mathrm{ns}}$ & $0,483^{\mathrm{ns}}$ & $-0,184^{\text {ns }}$ & $-0,399^{\text {ns }}$ & $0,144^{\mathrm{ns}}$ & $0,687^{*}$ & $-0,645^{*}$ \\
\hline
\end{tabular}

* Significativo pelo teste $\mathrm{F}(\mathrm{P}<0,05)$. ${ }^{\text {ns }}$ Não significativo 


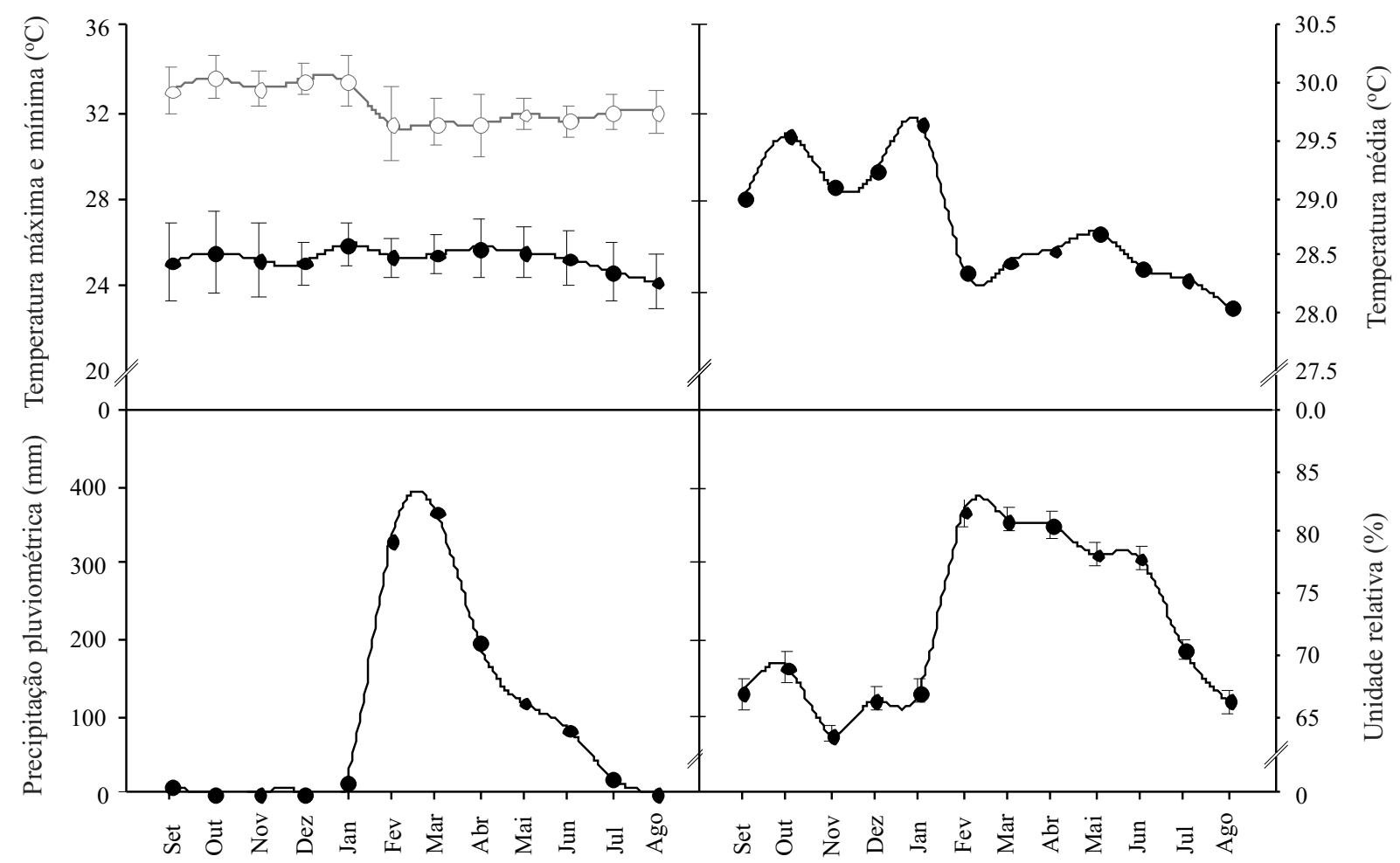

Figura 6 - Temperaturas mínima, máxima e média do ar, Umidade relativa e Precipitação pluviométrica da estação climatológica da Embrapa Agroindústria Tropical em Paraipaba, Ceará, monitoradas no período de setembro de 2006 a agosto de 2007. Os valores representam as médias mensais e as barras o desvio padrão

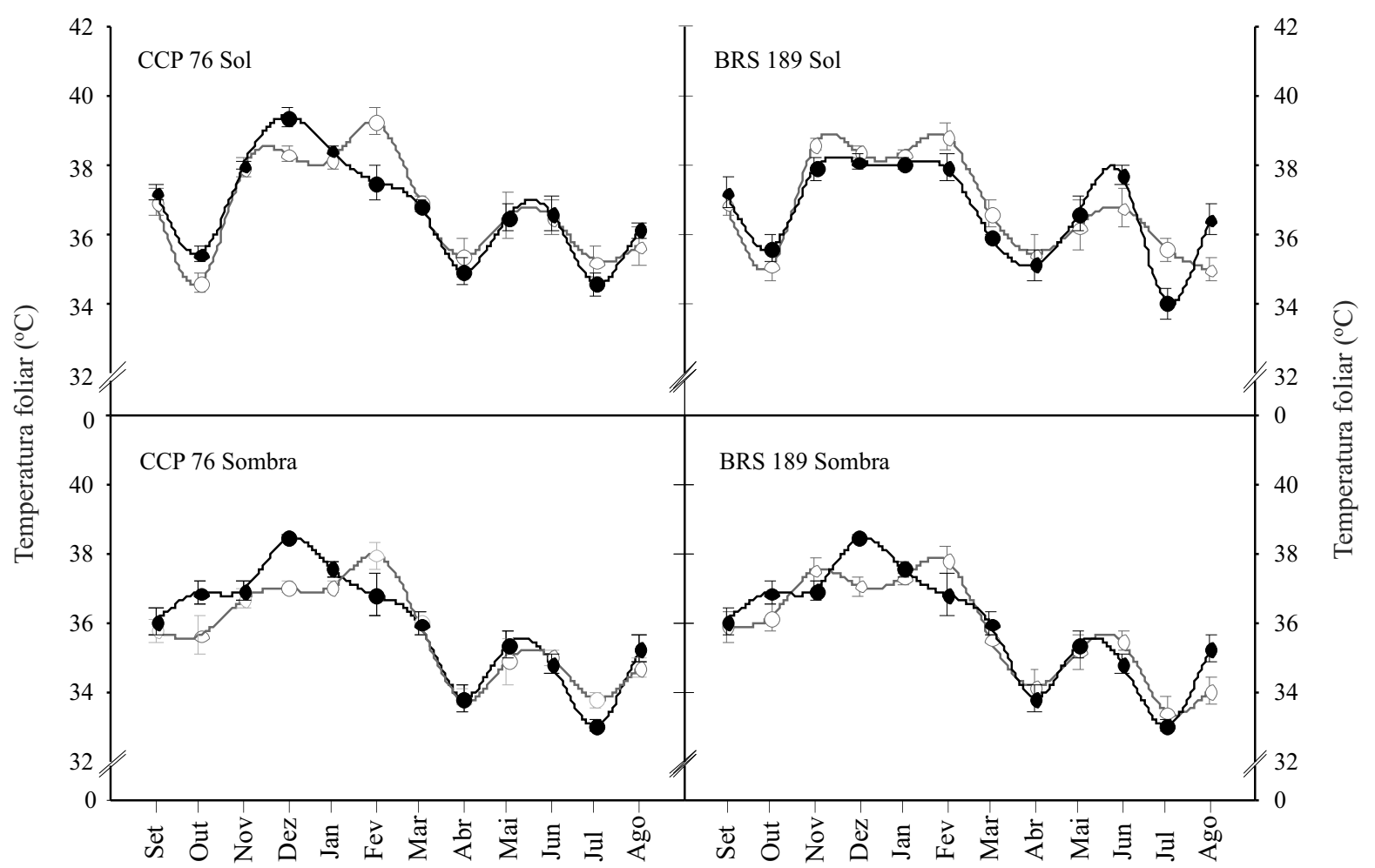

Figura 7 - Temperatura foliar de folhas a pleno sol e sombreadas, de plantas não irrigadas $(-\circ-)$ e irrigadas $(\bullet-)$, dos clones de cajueiro anão precoce CCP 76 e BRS 189 
A relação entre a concentração interna e externa de $\mathrm{CO}_{2}$ não foi alterada pelo regime hídrico aplicado (FIG. 8). Por outro lado, ela variou ao longo do experimento, aumentando pronunciadamente após o mês de março, atingindo o máximo no mês de maio, principalmente, para as folhas de sol. Nesse mês também foi observada, como mostram as Figuras 1 e 2, queda tanto na $g_{s}$ como na $A$ em ambos os clones e tipos de folhas.

Segundo Long e Bernacchi (2003), a redução na $A$, devido à limitação na $g_{s}$, deve causar uma diminuição na $\mathrm{C}_{\mathrm{i}}$, fato que ocorreu dos meses de setembro/2006 a fevereiro/2007. A diminuição na condutância estomática indica que a fotossíntese não estaria sendo restringida pelo fechamento estomático, nem pela concentração de $\mathrm{CO}_{2}$ dentro da câmara subestomática, mas por outros fatores bioquímicos que estariam dificultando a redução do $\mathrm{CO}_{2}$ ali existente (BELTRÃO, 2003; MARUR; FARIA, 2006). Os dados observados da Tabela 1 confirmam que não houve correlação entre as variáveis $A$ e $g_{s}$. Erismann et al.(2006) relatam que os valores de $A$ de folhas individuais são controlados pela necessidade do dreno em cultivares comercial de amendoim, indicando que o acúmulo de carboidratos na folha inibe a fotossíntese. Provavelmente, por ter sido o mês de maio o início da floração do cajueiro, onde a demanda por fotoassimilados é maior, as folhas sob condições não irrigadas podem ter sofrido uma maior dificuldade em atender a essa necessidade da planta.

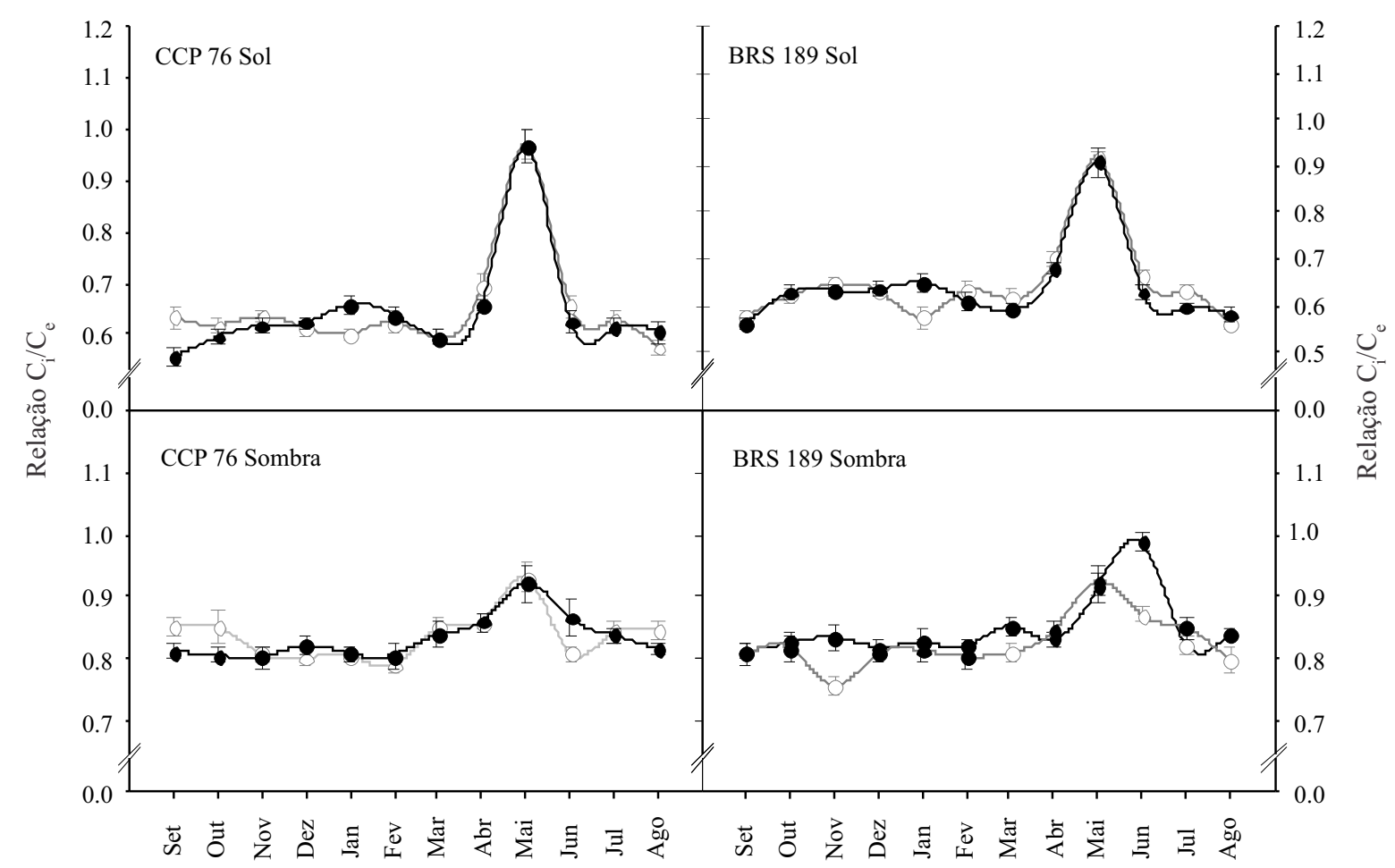

Figura 8 - Relação entre a concentração de $\mathrm{CO}_{2}$ interna e externa $\left(\mathrm{C}_{i} / \mathrm{C}_{e}\right)$ de folhas a pleno sol e sombreadas, de plantas não irrigadas $(-\circ)$ e irrigadas $(\bullet)$, dos clones de cajueiro anão precoce CCP 76 e BRS 189

\section{Conclusões}

1. As plantas de cajueiro anão precoce submetidas aos regimes hídricos, irrigado e não irrigado, tiveram seus parâmetros ecofisiológicos tais como fotossíntese, transpiração e condutância estomática, afetados apenas em algumas épocas do ano;

2. Maior influência nos fatores ecofisiológicos ocorreu pela luminosidade e fatores metereológicos para ambos os clones avaliados nesse experimento;
3. As plantas de cajueiro anão precoce possuem plasticidade quando em condições de sequeiro, conseguindo manter sua atividade metabólica e fisiológica vitais sem maiores danos à planta como um todo.

\section{Agradecimentos}

Os autores agradecem ao $\mathrm{CNPq}$ pelo apoio financeiro e pela bolsa de mestrado concedida ao primeiro autor e a Viviane Pinho Oliveira pela revisão do inglês. 


\section{Referências}

AMORIM, A. V. et al. Respostas fisiológicas de plantas adultas de cajueiro anão precoce à salinidade. Revista Ciência Agronômica, v. 41, n. 01, p. 113-121, 2010.

BELTRÃO, N. E. M. et al. Modificações na bioquímica da planta da mamoneira, cultivar BRS 188 Paraguaçu, submetida ao estresse hídrico (deficiência e excesso). Revista Brasileira de Oleaginosas e Fibrosas, v. 07, n. 01, p. 653-658, 2003.

BEZERRA, M. A. et al. Physiology of cashew plants grown under adverse conditions. Brazilian Journal of Plant Physiology, v. 19, n. 04, p. 449-461, 2007.

CASTRO NETO, M. T. Efeito do déficit hídrico na transpiração e resistência estomática da mangueira. Revista Brasileira de Fruticultura, v. 25, n. 1, p. 93-95, 2003.

CAVALCANTI, M. L. C. et al. Fisiologia do cajueiro anão precoce submetido à estresse hídrico em fases fenológicas. Revista de Biologia e Ciência da Terra, v. 08, n. 01, p. 42-53, 2008.

CAVALCANTI JÚNIOR, A. T.; MATOS, N. N.; SILVEIRA, J. A. G. Comportamento estomático do porta-enxerto CCP 06 e da muda enxertada CCP 76/06, submetidos aos estresses hídrico e salino. Fortaleza: Embrapa Agroindústria Tropical, 2003. $11 \mathrm{p}$.

DAMATTA, F. M. et al. Ecophysiology of coffee growth and production. Brazilian Journal of Plant Physiology, v. 19, n. 04, p. 485-510, 2007.

ERISMANN, N. M.; MACHADO, E. C.; GODOY, I. J. Capacidade fotossintética de genótipos de amendoim em ambiente natural e controlado. Pesquisa Agropecuária Brasileira, v. 41, n. 07, p.1099-1108, 2006.

GHANNOUM, O. et al. Nonstomatal limitations are responsible for drought-induced photosynthetic inhibition in four $\mathrm{C} 4$ grasses. New Phytologist, v. 159, n. 03, p. 599-608, 2003.

HABERMANN, G. et al. $\mathrm{CO}_{2}$ assimilation, photosynthetic light response curves, and water relations of 'Pera' sweet orange plants infected with Xylella fastidiosa. Brazilian Journal Plant Physiology, v. 98, n. 02, p. 79-87, 2003.

KANG, S. et al. Crop coefficient and ratio of transpiration to evapotranspiration of winter wheat and maize in a semihumid region. Agricultural Water Management, v. 59, n. 03, p. 239-254, 2003.

KUWAHARA, F. A.; SOUZA, G. M. Fósforo como possível mitigador dos efeitos da deficiência hídricas sobre o crescimento e as trocas gasosas de Brachiaria brizantha cv.MG-5 Vitória. Acta Scientiarum Agronomy, v. 31, n. 02, p. 261-267, 2009.

LARCHER, W. Ecofisiologia vegetal. São Carlos: Rima, 2000. $531 \mathrm{p}$.
LAWLOR, D. W.; CORNIC, G. Photosynthetic carbon assimilation and associated metabolism in relation to water deficits in higher plants. Plant, Cell and Environment, v. 25, n. 02, p. 275-279, 2002.

LONG, S. P.; BERNACCHI, C. J. Gas exchange measurements, what can they tell us about the underlying limitations of photosynthesis? Procedures and sources of error. Journal of Experimental Botany, v. 54, n. 392, p. 2393-2401, 2003.

MACHADO, E. C. et al. Variação sazonal da fotossíntese, condutância estomática e potencial da água na folha de laranjeira 'Valência'. Scientia Agricola, v. 59, n. 01, p. 53-58, 2002.

MACHADO FILHO, J.A. Estudos ecofisiológicos de dois genótipos de mamoeiro (Carica papaya L.) cultivados sob condições de campo no cerrado baiano. 2002. $70 \mathrm{f}$. Dissertação (Mestrado em Agronomia) - Universidade de Brasília, Brasília.

MACHADO-FILHO, J. A. et al. Variação sazonal das trocas gasosas em folhas de mamoeiro cultivado em condições de campo. Bragantia, v. 65, n. 02, p. 185-196, 2006.

MARUR, C. J.; FARIA, R. T. Photosynthesis of individual leaves in a coffee plant. Acta Scientiarium, v. 28, n. 03, p. 331-335, 2006.

OLIVEIRA, V. H.; LIMA; R. N. de. Influência da irrigação e da localização da inflorescência sobre a expressão do sexo em cajueiro não precoce. Pesquisa Agropecuária Brasileira, v. 35, n. 09, p. 1751-1758, 2000.

PAIVA, J. R.; BARROS, L. de M. Clones de cajueiro: obtenção, características e perspectivas. Fortaleza: Embrapa Agroindústria Tropical, 2004. 26 p.

PALlESCHI, S.; ROCHER, J. P.; PRIOUL, J. L. Sugar repression of photosynthesis: the role of carbohydrates in signalling nitrogen deficiency through source-sink inbalance. Plant, Cell and Environment, v. 20, n. 01, p. 110-116, 1997.

SANTOS, R. F.; CARLESSO, R. Déficit hídrico e os processos morfológico e fisiológico das plantas. Revista Brasileira de Engenharia Agrícola e Ambiental, v. 02, n. 03, p.287-294, 1998.

SILVA, E. A. et al. Seasonal changes in vegetative growth and photosynthesis of Arabica coffee trees. Field Crops Research, v. 08, n. 02 , p. 349-357, 2004.

SOUZA, G. M.; CARDOSO. V. J. M. Toward a hierarchical concept of plant stress. Journal of Plant Sciences, v. 51, n. 01, p. 29-37. 2003.

SOUZA, R. C.; SOARES, M. A; REGINA, A. M. Trocas gasosas de mudas de videira, obtidas por dois porta-enxertos, submetidas à deficiência hídrica. Pesquisa Agropecuária Brasileira, v. 36, n. 10, p. 1221-1230, 2001. 